\title{
Effect of Inlet Air Temperature on the Properties of Spray Dried San-sakng (Albertisia papuana Becc.) Leaf
}

\author{
Eva Mayasari ${ }^{1, a, *}$, Satrijo Saloko ${ }^{2, b}$, Oke Anandika Lestari ${ }^{1, \mathrm{c}}$, Maria Ulfa $^{2, \mathrm{~d}}$ \\ ${ }^{1}$ Faculty of Agriculture, Tanjungpura University, Pontianak, Indonesia \\ ${ }^{2}$ Faculty of Food Technology and Agroindustry, Mataram University, Mataram, Indonesia
}

*Corresponding author

\section{A R T I C L E I N F O A B S T R A C T}

Research Article

Free glutamic acid is a flavor enhancer compound that provided umami taste. San-sakng (Albertisia papuana Becc.) leaf has been used as a seasoning in the Dayaks tribe, West Kalimantan, Indonesia. The aim of this study was evaluated the effect of different drying inlet air temperature on physicochemical of the spray dried san-sakng leaf. San-sakng leaf powders was produced using spray drying and maltodextrin as raw material. Completely randomized design was used with one factor, namely drying inlet air temperature on the spray drying process $\left(130^{\circ} \mathrm{C}, 140^{\circ} \mathrm{C}\right.$, and $\left.150^{\circ} \mathrm{C}\right)$. The results showed that moisture, solubility, bulk density, particle size, and encapsulation efficiency on the San-sakng leaf powders presented significantly affected by the drying inlet air temperature.

Received : 02/09/2019 Accepted : 14/05/2020 Increasing inlet air temperature led to reduced moisture, bulk density, and particle size, whereas

Keywords:

Spray drying enhancing the solubility and encapsulation efficiency.

Free glutamic acid

Maltodextrin

Temperature

Umami

\section{Introduction}

Flavourings are used as food additives for altering and enhancing the taste and/or aroma of food products. Reineccius (2005) explains that flavour enhancer is a substance that has no flavour (at level effects) but also intensifies or improve the taste of food. Zuhra (2006) argue that flavour enhancer as material that can improve the delicious taste or pressing of undesired taste. flavour enhancer substances that are obtained from plant or animal raw materials, by physical, microbiological or enzymatic processes are classified as natural flavouring substances. Flavour enhancer produces umami taste in foodstuff. Glutamic acid is a flavour enhancer compound that provides umami taste (Rangan and Barceloux, 2009). Among other amino acids that only free glutamic acid form as a flavour enhancer in the food industry (Populin et al., 2007). Free glutamic acid can be found in both plant and animal foodstuff. Vegetable foodstuff such as kombu, nori, tamarillio, tomato, macambo, garlic, potato, chinese cabbage, carrot, onion, and seafood such as scallop, shrimp, sea urchin, short necked clam, crab, egg yolk (Kurihara, 2009).
San-sakng (Albertisia papuana Becc.) leaf has been used as a flavour enhancer in the Dayaks tribe, West Kalimantan, Indonesia. Mayasari et al. (2015) reported that the san-sakng leaves extract identified free amino acid content of $40.44 \mathrm{mg} / \mathrm{g}$ dry weight. Mayasari et al. (2016) study emphasize that the addition of san-sakng leaf on local dishes such as vegetable is generally in fresh leaf. The lack of utilization of fresh leaves form is impractical and slightly shorter shelf life.

Encapsulation is the process of trapping a substance in another substance which is the ability to protect the bioactive component from destructive changes, transmute it into the form of flour, and protect its flavour (Zuidam and Shimoni, 2009; Shaikh et al., 2006; Estevinho et al. 2013). Spray drying is one of the useful techniques of the encapsulation process for changing liquids into solid powder form which is not only practice handling but also extends shelf life and improves the stability of food production. (Cai and Corke, 2000). During the encapsulation process, it is necessary to protect bioactive component with encapsulating product are appropriate, 
encapsulate ratio, drying inlet and outlet temperature, and drying flow rate (Gharsallaoui et al., 2007; Yu et al., 2010).

Maltodextrin (MD) is a suitable wall material because it is more effective, bland in flavour, low viscosity at a high solid ratio and is available in a variety of molecular weights (Apintanapong and Noomhorm, 2003). Several studies confirm that MD potentials in preserving vitamin $C$ in fruit juice and stability of acerola powder (Righetto and Netto, 2005). Several studies have been shown that the impact of drying inlet air temperature for the encapsulation process. $140-150^{\circ} \mathrm{C}$ inlet air temperature for encapsulation vanillin extract (Setyaningsih et al., 2007). $150^{\circ} \mathrm{C}$ inlet air temperature is the best treatment for pineapple powder (Suzihaque et al., 2015). Therefore, the aim of this study was to evaluate the effect of different drying inlet air temperature $\left(130^{\circ} \mathrm{C}, 140^{\circ} \mathrm{C}\right.$, and $\left.150^{\circ} \mathrm{C}\right)$ on physicochemical of the spray dried san-sakng leaf.

\section{Materials and Methods}

\section{Preparation of Raw Materials}

The raw materials for the preparation of this study were san-sakng leaf, maltodextrin (MD) with Dextrose Equivalent (DE) $10.8 \%$, and $\mathrm{NaCl}$. San-sakng leaf was dried in a cabinet dryer at $50^{\circ} \mathrm{C}$ temperature until $10 \%$ moisture content. The leaf powder obtained from dried leaf was ground and sieved by 60 mesh sieve. The leaf powder was stored in the dark at a low temperature $\left(-20^{\circ} \mathrm{C}\right)$ until used.

\section{Water Soluble Extract Preparation}

Water soluble extract (WSE) preparation was followed from Mayasari et al. (2016) in the previous study, the extract was obtained by infusion extraction method. 1 gram of leaf powder was diluted in $100 \mathrm{ml}$ solution of boiling aquades at $90^{\circ} \mathrm{C}$. The mixture solution was homogenized for 1 minute by vortex for 15 minute. The homogenized solution was vacuum filtered, then the residues were reextracted with the same process as explained in the previous stage. The collected filtrate was added $0.6 \%$ $\mathrm{NaCl}$, then homogenized for 1 minute by the vortex. Filtrate stored at freezing temperature $\left(-20^{\circ} \mathrm{C}\right)$ until used.

\section{Preparation of Encapsulation}

MD was dissolved to distilled water with 1:1 ratio at room temperature. MD solution was added to san-sakng leaf extract, the total solid concentration (MD + extract) was set at $10 \%$. This mixture was agitated using a magnetic stirrer at $200 \mathrm{rpm}$ for $30 \mathrm{~min}$ at room temperature. The supernatant was vacuum filtered using Whatman No.2. It was heated in a waterbath at the temperature of $50^{\circ} \mathrm{C}$. The subsequent homogenization process used the turrax (homogenizer ultra turrax T50) for 2,5 minutes at 4000 rpm. The homogeneous solution was filtered using a vacuum filter with Whatman filter paper no.41 (Ahn et al., 2008; Saloko et al., 2012).

\section{Drying Condition}

Drying condition was performed referring to Saloko et al. (2012). The homogenous solution was fed into a Buchi B-290 minute spray dryer (Flawii, Switzerland) for drying. The operating conditions were as follows; aspirator rate $50 \%$; drying inlet air temperature $130^{\circ} \mathrm{C}, 140^{\circ} \mathrm{C}$, and $150^{\circ} \mathrm{C}$, while the outlet air temperature varied between $82^{\circ} \mathrm{C}$; feed flow rate was set at $5.1 \mathrm{ml} /$ minute; atomization air rotameter $30 \mathrm{~mm}$ and the nozzle cleaner set to 4 . Spraydried powders kept in vacuum sealer polyethylene and stored at room temperature.

\section{Moisture Content}

The moisture content of powder determined following to the AOAC (2008) methods. The sample was measured by a hot air oven at $105^{\circ} \mathrm{C}$ for constant weight.

\section{Solubility}

The solubility described according to the Eastman and Moore method (Cano et al., 2005) with some modification by Avila et al. (2015). The san-sakng powder (1 g) was homogenized in $50 \mathrm{~mL}$ distilled water in a vortex for 30 seconds. The san-sakng solution centrifuged at 3,000 rpm for $5 \mathrm{~min}$ at $25^{\circ} \mathrm{C}$. A $25 \mathrm{~mL}$ aliquot of the supernatant was placed to Petri dishes. Then, drying in an oven at $105^{\circ} \mathrm{C}$ for $5 \mathrm{~h}$. The solubility spray dried san-sakng leaf was calculated as the initial weight minus the final weight divided by the initial weight.

\section{Morphological Examination}

The morphology of spray dried product was determined by a scanning electron microscope (SEM FEI, Inspect S50, Oregon, USA). The morphology was used to study the surface characteristic of the powder. The powder was coated with gold and measured at 10,000 magnifications.

\section{Bulk Density}

Bulk density was determined by weighing \pm 1 gram of powder, then it is transferred to $50 \mathrm{~mL}$ graduated cylinder. Packed bulk density was recorded after rapped gently the cylinder by hand for 50 times from a height of $10 \mathrm{~cm}$ (Goula and Adamopoulos, 2004).

\section{Particle Size Distribution}

The product spray dried was measured according to Carneiro et al. (2013) method that particle size distribution of sizes formed using a laser particle size distribution analyzer (Malvern Zetasizer Nanoseries Nano ZS Ver 6.20, Malvern Instruments Ltd, Malvern, UK). The particle size distribution was expressed until successive readings became constant.

\section{Encapsulation Efficiency}

Encapsulation efficiency (EE) was expressed by free glutamic acid content. Determination of free glutamic acid content was established following to modification from Purwayantie et al. (2015) methods. $100 \mathrm{mg}$ of powder were dissolved in $10 \mathrm{ml}$ aquades, then vacuum filtered. $4 \mathrm{ml}$ from supernatant centrifuged for $2 \mathrm{~min} .25 \mu \mathrm{l}$ of supernatant were mixed with $300 \mu \mathrm{l}$ of OPA (o-Phthaldialdehyde) solution, vortexed for $1 \mathrm{~min}$. $20 \mu \mathrm{l}$ aliquot was injected and analysed using HPLC (SHIMADZU LC 10) with a Licrospher 100 $\mathrm{RP} 18(5 \mu \mathrm{m})$ and a $125 \times 4 \mathrm{~mm}$ column. The separation of OPA-derivatives was performed using a mobile phase consisting of methanol, 50mM Na-acetate, THF (2:9:2) at pH 6.8 as solvent A and $65 \%$ methanol as solvent B. The gradient elution program was held at $100 \%$ of A for $0.1 \mathrm{~min}$, ramped at $100 \%$ of $\mathrm{B}$ for $45 \mathrm{~min}$ and stopped at 50 minutes with a flow rate of $1 \mathrm{ml} / \mathrm{min}$. Detection was set at $360 \mathrm{~nm}$ (Ex) and 460nm (Em). Free glutamic acid was measured by 
using the authentic standard (Sigma-Aldrich) and quantified by the calibration curve of the external standard.

\section{Statistical Analysis}

All data resulted were analysed based on Completely Randomized Design at a confidence level of $95 \%$. Significances of averages were calculated with a DMRT using SPSS version 15.0 software. All data were performed in triplicates.

\section{Results and Discussion}

\section{Moisture Content}

The moisture content affects the quality of the food product. Table 1 showed that the percentage of moisture content of san-sakng powder varied between 0.70 to $1.01 \%$. Analysis of variance showed significant differences $(\mathrm{P}<0.05)$, that increase inlet air temperature will decrease moisture content. This is due to Phisut (2012) explains that the higher inlet air temperature gives the greatest driving force for water evaporation. Hence it, the moisture content will decrease by increase the drying inlet air temperature.

\section{Solubility}

Table 1 showed that the percentage of solubility of sansakng powder varied between 97.98 to $98.10 \%$. Analysis of variance showed significant differences $(\mathrm{P}<0.05)$, that increase inlet air temperature will increase solubility. The maltodextrin was a carrier exhibited good solubility and added no flavour or odour to the final product (Kenyon, 1995; Wang and Wang, 2000). Ersus and Yurdagel (2007) states that maltodextrin given a high values of solubility in water. Solubility is directly related to the microstructure of the powder. A larger amorphous surface means that the powder will have more solubility in water (Cano et al., 2005).

\section{Particle Size Distribution}

The particle size of san-sakng powders was 43.14 to $101.71 \mathrm{~nm}$ (Table 1). Analysis of variance showed significant differences $(\mathrm{P}<0.05)$, that the higher temperature decreases the particle size. This result is due to Chegini and Ghobadian (2005) states that increasing inlet air temperature gives a rapid formation on the droplet surface. Therefore, particle size change beside the skinning over or case hardening on the droplets at the higher temperature. It leads to the formation of favourimpermeable films on the droplet surface followed by the formation of vapour bubbles and the droplet expansion.

\section{SEM of Spray Dried San-sakng Leaf}

A representative scanning electron microscopy (SEM) of the spray dried san-sakng powder determined at magnification 10000x in Figure 1. The features showed that the all the samples using inlet air temperature $130^{\circ} \mathrm{C}$, $140^{\circ} \mathrm{C}$, and $150^{\circ} \mathrm{C}$ presented spherical particles with wrinkled surfaces. These similar features have been found in spray-dried coconut shell liquid smoke powder (Saloko et al., 2012). This phenomenon was suggested that under processing method. Chin et al. (2010) states that particles with wrinkled surfaces resulted in spray drying are caused by particle shrinkage during the process drying. Patel et al. (2009) argue that spherical particles have a large surface or volume ratio that suitable for spray drying products.

\section{Encapsulation Efficiency}

Free glutamic acid is the taste-active compound found in natural sources (Ninomiya, 1998). The free glutamic acid compound developed flavour enhancer was analysed by HPLC. According to the result in Figure 2, free glutamic acid was identified in the WSE san-sakng leaf and spray dried powders at different drying inlet air temperature by comparing peak retention time with amino acid standard. The encapsulation efficiency of glutamic acid varied between 94.49 to $96.85 \%$ (Table 1). Analysis of variance showed significant differences $(\mathrm{P}<0.05)$. The optimum condition of inlet air temperature was achieved at temperature $140^{\circ} \mathrm{C}$ that produced the highest encapsulation efficiency was $96.85 \%$. In relation to the SEM of particle features that spherical features can retain the highest amount of flavouring agents (Reineccius, 2004).

Table 1. Characterization of Spray Dried San-sakng Leaf at Different Inlet Air Temperature $\left(130^{\circ} \mathrm{C}, 140^{\circ} \mathrm{C}\right.$, and $\left.150^{\circ} \mathrm{C}\right)$

\begin{tabular}{c|ccccc}
\hline \multirow{2}{*}{$\begin{array}{c}\text { Inlet Temperature } \\
\left({ }^{\circ} \mathrm{C}\right)\end{array}$} & \begin{tabular}{c}
$\mid c$ \\
Moisture \\
\cline { 2 - 6 }
\end{tabular} & $\begin{array}{c}\text { Solubility } \\
(\%)\end{array}$ & $\begin{array}{c}\text { Bulk Density } \\
(\mathrm{g} / \mathrm{mL})\end{array}$ & $\begin{array}{c}\text { Particle Size } \\
(\mathrm{nm})\end{array}$ & $\begin{array}{c}\text { Encapsulation } \\
\text { Efficiency }(\%)\end{array}$ \\
\hline 130 & $1.01 \pm 0.03^{\mathrm{c}}$ & $97.98 \pm 0.05^{\mathrm{a}}$ & $0.53 \pm 0.02^{\mathrm{c}}$ & $101.71 \pm 0.11^{\mathrm{c}}$ & $94.49 \pm 0.08^{\mathrm{a}}$ \\
140 & $0.87 \pm 0.01^{\mathrm{b}}$ & $98.08 \pm 0.03^{\mathrm{b}}$ & $0.46 \pm 0.34^{\mathrm{ab}}$ & $73.99 \pm 0.54^{\mathrm{b}}$ & $96.85 \pm 0.07^{\mathrm{c}}$ \\
150 & $0.70 \pm 0.01^{\mathrm{a}}$ & $98.10 \pm 0.03^{\mathrm{c}}$ & $0.46 \pm 0.03^{\mathrm{a}}$ & $43.14 \pm 0.87^{\mathrm{a}}$ & $95.33 \pm 0.01^{\mathrm{b}}$ \\
\hline
\end{tabular}

$\overline{a, b, c}$ The different letters in the same line represent that there are significant differences at the level of $\mathrm{P}<0.05$, and the same letters represent no significant difference

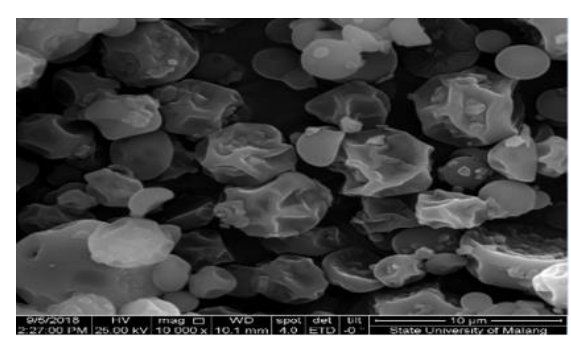

(a)

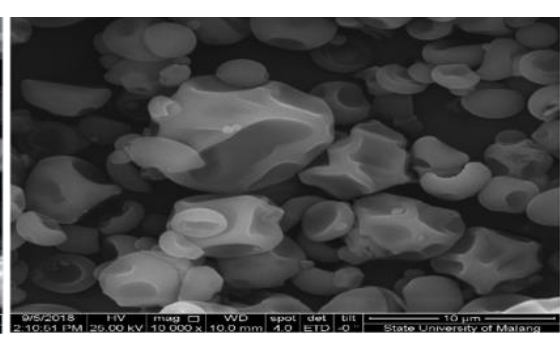

(b)

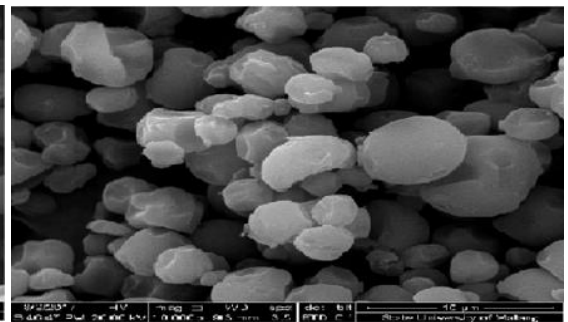

(c)

Figure 1. Scanning Electron Microscopy (SEM) Images of Spray Dried San-sakng Leaf at $10.000 \mathrm{x}$ magnification at Different Inlet air Temperature (a) $130^{\circ} \mathrm{C},\left(\right.$ b) $140^{\circ} \mathrm{C},(\mathrm{c}) 150^{\circ} \mathrm{C}$ 


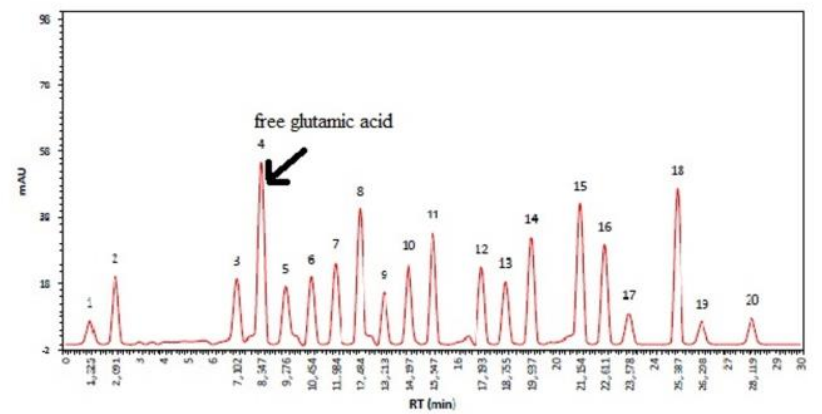

(a)

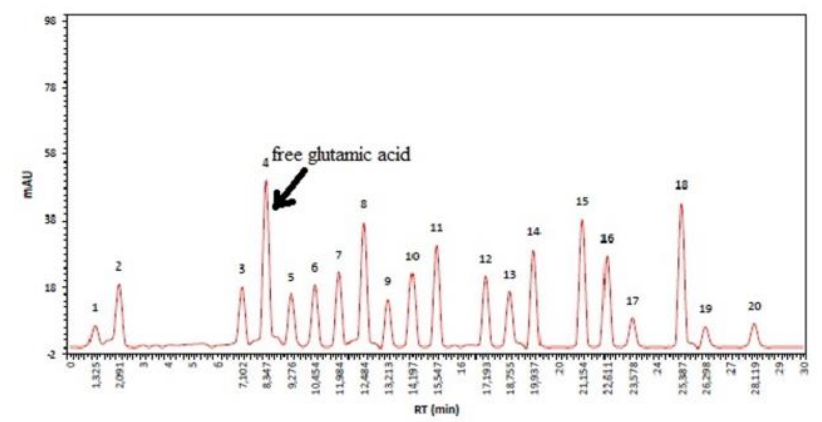

(c)

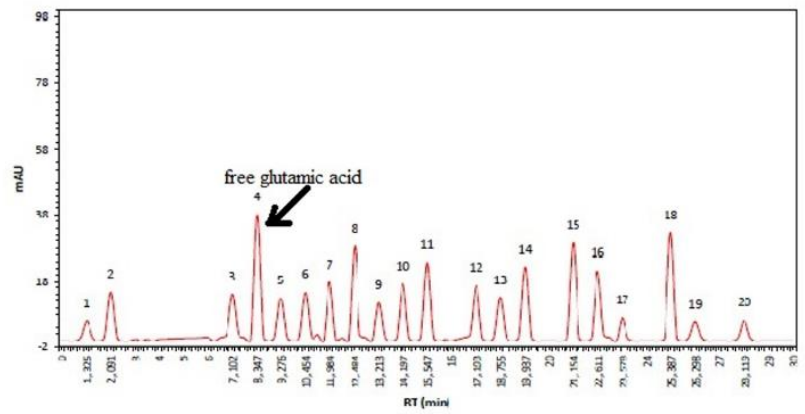

(b)

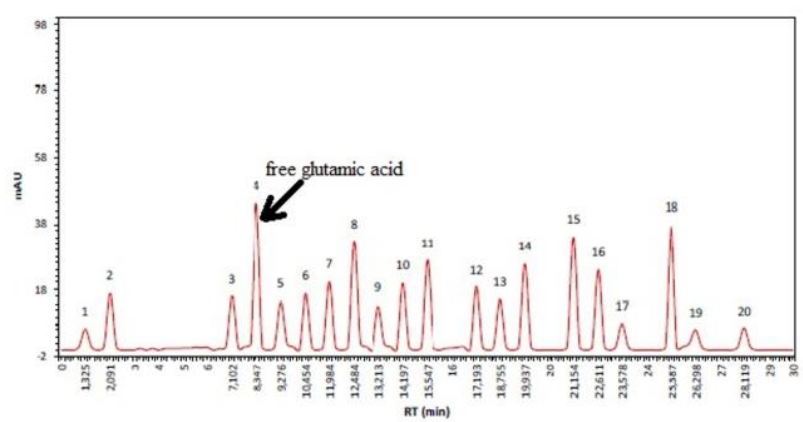

(d)

Figure 2. Free Glutamic Acid Content of Spray Dried San-sakng Leaf at Different Inlet Air Temperature; (a)WSE san-sakng leaf; (b) $130^{\circ} \mathrm{C}$; (c) $140^{\circ} \mathrm{C}$; (d) $150^{\circ} \mathrm{C}$

\section{Bulk Density}

The values of bulk density were in the range of 0.46 $0.53 \mathrm{~g} / \mathrm{mL}$ (Table 1). Analysis of variance showed the inlet air temperature have a significance difference $(\mathrm{P}<0.05)$, that increase inlet air temperature will decrease bulk density of spray dried san-sakng leaf. These similar results have been found in grape syrup powder obtained by spray drying (Sarabandi et al., 2014). According to Walton (2000) increasing the drying air temperature generally produces a decrease in bulk and particle density.

\section{Conclusion}

The results of this study confirm that different drying inlet air temperature impacted to the san-sakng extract powder quality. As a conclusion the different inlet air temperature in drying process influences the moisture, solubility, bulk density, particle size, and encapsulation efficiency. The higher drying inlet air temperature decreases moisture, bulk density, and particle size, whereas the solubility and encapsulation efficiency is increased.

\section{Acknowledgments}

We sincerely acknowledge for The Ministry of Research, Technology and Higher Education of Indonesia was provided this research funding.

\section{References}

Ahn JH, Kim YP, Lee YM, Seo EM, Lee KW, Kim HS. 2009. Optimization of Microencapsulation of Seed Oil by Response Surface Methodology. Food Chemistry 107 (1), 98-105. DOI: 10.1016/j.foodchem.2007.07.067
AOAC. 2008. Official methods of analysis of AOAC International. 16th ed. Gaithersburg, Maryland. AOAC International. ISBN: 0-935584-42-0.

Apintanapong M, Noomhorm A. 2003. The Use of Spray-Drying To Microencapsulate 2-acetyl-1 pyrroline, a Major Flavour Component of Aromatic Rice. International Journal of Food Science and Technology 38: 95-102. DOI: 10.1046/j.13652621.2003.00649.x

Avila EL, Misael CR, Héctor JCV. 2015. Influence of Maltodextrin and Spray Drying Process Conditions on Sugarcane Juice Powder Quality. Rev.Fac.Nal.Agr.Medellín 68(1): 7509-7520. doi: http://dx.doi.org/10.15446/ rfnam. v68n1.47839

Cai YZ, Corke H. 2000. Production and Properties of Spray-dried Amaranthus Betacyanin Pigment. Journal of Food Science 65(6): 1248-125. DOI:10.1111/j.1365-2621.2000.tb10273.x

Cano M, Stringheta, PC, Ramos AM, Cal-Vidal J. 2005. Effect of the carriers on the microstructure of mango powder obtained by spray drying and its functional characterization. Innovative Food Science and Emerging Technologies 6(4): 420-428. http://dx.doi.org/10.1016\%2Fj.ifset.2005.05.003

Carneiro HCF, Tonon RV, Grosso CRF, Hubinger MD. 2013. Encapsulation efficiency and oxidative stability of flaxseed oil microencapsulated by spray drying using different combinations of wall materials. Journal of Food Engineering 115: 443-451. DOI:10.1016/j.jfoodeng.2012.03.033

Chegini GR, Ghobadian B. 2005. Effect of Spray-drying Conditions On Physical Properties of Orange juice powder. Drying Technology 23 (3): 657-668. DOI:10.1081/DRT200054161

Ersus S, Yurdagel U. 2007. Microencapsulation of anthocyanin pigments of black carrot (Daucus carota L.) by spray drier. Journal of Food Engineering 80(3): 805-812.

Estevinho BN, Rocha F, Santos L, Alves A. 2013. Microencapsulation With Chitosan by Spray Drying for Industry Applications - A review. Trends In Food Science \& Technology, 31:138-155. DOI:10.1016/j.tifs.2013.04.001 
Goula AM, Adamopoulos KG. 2004. Spray Drying of Tomato Pulp: Effect of Feed Concentration. Drying Technology 22 (10), 2309-2330. DOI: 10.1081/DRT-200040007.

Gharsallaoui A, Roudaut G, Chambin O, Voilley A, Saurel R. 2007. Applications of Spray-drying In Microencapsulation of Food Ingredients: An overview. Food Research International, 40:1107-1121. DOI: 10.1016/j.foodres.2007.07.004

Kenyon MM. 1995. Modified starch, maltodextrin, and corn syrup solids as wall materials for food encapsulation. ACS Symposium Series 590: 42-50.

Kurihara K. 2009. Glutamate. From Discovery as a Food Flavor to Role as a Basic Taste (Umami). American Journal of Clinical Nutrition, 90. 71957225. DOI: 10.3945/ajcn.2009.27462D

Mayasari E, Supriyadi US. 2015. Identifikasi Asam Glutamat Bebas Daun Sokai Segar (Albertisia papuana Becc.). Jurnal Ilmiah Agrosains Tropis. Volume 8. No. 4. Hal. 199-203. ISSN: 1907-1256

Mayasari E. 2016. Pengaruh Tingkat Ketuaan Daun Sokai Segar (Albertisia papuana Becc.) Terhadap Kadar Asam Amino Glutamat Bebas. Jurnal Ilmiah Teknosains. Vol. 2. No. 1. 38 42. DOI: http://dx.doi.org/10.26877/jitek.v2i1/Mei.1012

Ninomiya K. 1998. Natural Occurance. Food Review International. 14: 2-3, 177-211. DOI: 10.1080/87559129809541157

Populin T, Moret S, Truant S, Conte dan S. 2007. A Survey on the Presence of Free Glutamic Acid in Foodstuffs, With and Without Added Monosodium Glutamate. Food Chemistry. 104 1712-1717. DOI: 10.1016/j.foodchem.2007.03.034

Purwayantie S, Santoso U, Supriyadi GM, Susanto H. 2015. The Isolation of Taste Compounds in Bekkai lan (Albertisia papuana Becc.) Leaves Extract Using Nanofiltration. International Food Research Journal. 22 (1): 225-232. ISSN: $1985-4668$

Rangan C, Barceloux DG. 2009. Food additives and sensitivities. Dis Mon; 55: 292-311. DOI: 10.1016/j.disamonth.2009.01.004

Reineccius GA. 2004. The spray drying of food flavors. Drying Technology, 22(6): 1289-1324, DOI: 10.1081/DRT120038731
Righetto AM, Netto FM. 2005. E ffect of Encapsulation Materials On Water Sorption, Glass Transition, and Stability of Juice From Immature acerola. International Journal of Food Properties, 8: 337-346. DOI: 10.1081/JFP-200060262

Saloko SDP, Bambang S, Pranoto Y. 2012. Structural Analysis of Spray-Dryed Coconut Sheel Liquid Smoke Powder. J. Teknol dan Industri Pangan. Vol. XXIII. No. 2. 173-179. DOI: https://doi.org/10.6066/jtip.2012.23.2.173

Sarabandi K, Seyed HP, Majid S. 2014. Physical Properties Of Spray Dried Grape Syrup as Affected by Drying Temperature and Drying Aids. Intl J Agri Crop Sci (IJACS). 12: 928-934. ISSN 2227-670X

Setyaningsih D, Rahmalia R, Sugiyono 2007. Kajian Mikroenkapsulasi Ekstrak Vanili. Jurnal Teknologi dan Industri Pertanian, 19: 64-70

Shaikh J, Rajesh B, Rekha S. 2006. Microencapsulation of Black Pepper Oleoresin. Food Chemistry (94): 105-110. DOI: 10.1016/j.foodchem.2004.10.056

Suzihaque MUH, Syafiza AH, Ummi KI. 2015. Effect of Inlet air temperature on Pineapple Powder and Banana Milk Powder. Procedia-Social and Behavioral Sciences 195. 2829-2838. DOI: https://doi.org/10.1016/j.sbspro.2015.06.401

Walton DE. 2000. The morphology of spray-dried particles. A qualitative view. Drying Technology, 18, 1943-1986.

Wang YJ, Wang L. 2000. Structures and properties of commercial maltodextrins from corn, potato, and rice starches. Starch-Stärke 52(8-9): 296-304.

Yu C, Ma J, Wang W. 2010. Preparation of Redispersible Emulsion Powder by Spray Drying. International Journal of Food Engineering, 2: 10.

Zuhra, C.F. 2006. Flavor (Cita Rasa). Karya Ilmiah. USU Respitory.

Zuidam NJ, Nedovic VA. 2009. Encapsulation Technologies for Food Active Ingredients and Food Processing. Springer: Dordrecht, The Netherlands. Pg. 3-31. DOI:10.1007/978-14419-1008-0 